\title{
Protein Kinase C Signal Transduction Regulation in Physiological and Pathological Aging
}

\author{
FIORENZO BATTAINI ${ }^{a}$ AND ALESSIA PASCALE ${ }^{b}$ \\ a Department of Neuroscience, University of Roma “Tor Vergata," Rome, Italy \\ ${ }^{b}$ Department of Experimental and Applied Pharmacology, University of Pavia, \\ Pavia, Italy
}

\begin{abstract}
Calcium/phospholipid-regulated protein kinase C (PKC) signalling is known to be involved in cellular functions relevant to brain health and disease, including ion channel modulation, receptor regulation, neurotransmitter release, synaptic plasticity, and survival. Brain aging is characterized by altered neuronal molecular cascades and interneuronal communication in response to various stimuli. In the last few years we have provided evidence that in rodents, despite no changes in PKC isoform levels (both calcium dependent and calcium independent), the activation/translocation process of the calcium-dependent and -independent kinases and the content of the adaptor protein RACK1 (receptor for activated C kinase-1) are deficient in physiological brain aging. Moreover, human studies have shown that PKC and its adaptor protein RACK1 are also interdependent in pathological brain aging (e.g., Alzheimer's disease); in fact, calcium-dependent PKC translocation and RACK1 levels are both deficient in an area-selective manner. These data point to the notion that, in addition to a well-described lipid environment alteration, changes in protein-protein interactions may impair the mechanisms of PKC activation in aging. It is interesting to note that interventions to counteract the age-related functional loss also restore $\mathrm{PKC}$ activation and the adaptor protein machinery expression. A better insight into the factors controlling PKC activation may be important not only to elucidate the molecular basis of signal transmission, but also to identify new strategies to correct or even to prevent agedependent alterations in cell-to-cell communication.
\end{abstract}

KEYWORDS: protein kinase C; PKC; isoforms; isozymes; aging; brain; RACK1; anchoring; scaffolding; translocation; Alzheimer's disease; pineal transplant

\section{SIGNAL TRANSDUCTION IN BRAIN AGING}

Intracellular communication represents a key element of the molecular alterations associated with senescence, resulting in modifications of cell function and, at

Address for correspondence: Fiorenzo Battaini, Ph.D., University of Roma, Tor Vergata School of Medicine, Department of Neurosciences, Via Montpellier 1, 00133 Rome, Italy. Voice: +3906 7259 6304/6310; fax: +390672596302.

Battaini@med.uniroma2.it

Ann. N.Y. Acad. Sci. 1057: 177-192 (2005). () 2005 New York Academy of Sciences. doi: 10.1196/annals.1356.011 
a more integrated level, in cognitive and neurological impairments. In this context, the aging process can affect signal transduction at different levels from receptor availability and coupling with effectors systems to the production of second messengers and the activation of protein kinases and phosphatases. Current research is focusing on the molecular mechanisms of neuronal communication as possible targets for intervention to ameliorate age-related functional decay and to prevent cell degeneration. ${ }^{1}$

An important concept that has emerged in recent studies utilizing stereological techniques of neuronal count during physiological brain aging in humans, is that contrary to the original morphological studies showing age-related neuronal loss in cortical structures, neuronal loss is not evident between ages 60 and $90 .^{2}$ Moreover, no neuronal decline is present in the hippocampus of aged rats showing age-related deficits in the water-maze task, providing evidence that the behavioral impairments observed during senescence are not associated with neuronal degeneration in the hippocampus. ${ }^{3}$ It therefore appears that although cortical and hippocampal neurons may not degenerate during aging, other alterations - such as those implying changes in cell-to-cell communication-may affect cerebral functions. The primum movens toward age-related changes may thus be related to alterations in signal transduction cascades and not to morphological deficits.

Protein modification by phosphorylation is a relevant regulatory tool utilized by all cells within various aspects of signal transduction under both physiological and pathological conditions. It represents the "final common pathway" in the actions of various transmitters and it can also constitute an important regulatory feedback mechanism for some of the steps involved in the production of intracellular second messengers. Several protein kinases have been reported to play critical roles in brain functions and protein kinase $\mathrm{C}$ is widely recognized as one of the relevant players in the regulation of learning and memory phenomena. ${ }^{4,5}$

\section{FOCUS ON PROTEIN KINASE C ISOZYMES}

The serine/threonine kinases, protein kinases C (PKCs) are a family of enzymes (at least 10 isoforms) highly expressed and functionally operating in brain tissues, transducing signals coupled to receptor-mediated hydrolysis of membrane phospholipids. ${ }^{6}$ These enzymes transduce signals that regulate short-term events (ion fluxes, neurotransmitter release), mid-term events (receptor modulation), as well as longterm events (synaptic remodeling and gene expression). Brain tissues express all $\mathrm{PKCs}^{7}$ and, in spite of sequence and structural homologies among the different PKCs, each isoform may have unique roles resulting from specific activation-dependent subcellular localization and substrate phosphorylation.

While the C-terminal catalytic domain of PKC shows homology among the different isoforms, the regulatory $\mathrm{N}$-terminal sequence confers enzyme diversity and is the site where interaction with activators occurs. The regulatory domain binds and it is activated by calcium, DAG, phosphatidylserine (PtdSer), and other lipids (see below). Activation of PKCs is associated with the movement or translocation of each single isoform from a compartment (where PKC is catalytically inactive) to another (where it becomes catalytically active) where PKC finds the specific activators. PKC is kept in an inactive "folded" conformation by binding of the pseudosubstrate 
sequence (in the regulatory region) to the substrate binding site (in the catalytic region). ${ }^{8,9}$

PKCs are classified as calcium-dependent, calcium-independent, and atypical isozymes according to their sensitivity to calcium and diacylglycerol. The membrane lipid PtdSer sustains the activity of all PKCs. The conventional or calcium-dependent PKCs (cPKCs: $\alpha, \beta \mathrm{I}, \beta \mathrm{II}$, and $\gamma$ ) require additional free calcium and diacylglycerol (DAG) for complete activation. The calcium-independent novel PKCs (nPKCs: $\delta, \varepsilon, \eta$, and $\theta$ ) are fully activated by DAG only, whereas the atypical PKCs (aPKCs: $\zeta$ and $\lambda / \mathrm{l}$ ) are calcium- and DAG-independent. ${ }^{8}$ The tumor promoters phorbol esters can mimic DAG in PKCs activation. Two DAG-dependent kinases formerly described as additional members of the PKC family ( $\mu$ and $v$ ) are now classified as protein kinases $\mathrm{D}$, sharing better homology with the catalytic domain of calcium/calmodulin kinases. ${ }^{10}$

\section{REGULATION OF PKC ACTIVATION}

\section{Phosphorylation}

The structure, subcellular localization, and function of PKCs are regulated by upstream and downstream events involving the inactive different isozymes. Upstream events are characterized by a cascade of phosphorylating reactions taking place on the catalytic domain of the nascent PKCs. ${ }^{8}$ These "priming" phosphorylations are important to make PKCs responsive to activators. The newly synthesized "immature" kinases are initially phosphorylated as membrane-bound enzymes by a phosphoinositide-dependent kinase-1(PDK-1), which is modulated by $3^{\prime}$ phosphoinositides produced by phosphoinositide 3-kinase (PI 3-kinase) ${ }^{9}$ The PDK-1 phosphorylation permits the subsequent autophosphorylation of two additional residues in the catalytic domain: at this point PKC is "mature" and released as the soluble form (inactive) able to respond to activators. The importance of PDK-1 for native PKC is underscored by the observation that deletion of PDK-1 dramatically decreases the levels of PKC isozymes. ${ }^{11}$

Downstream events are characterized by the binding of PKCs with their activators.

\section{Protein-Lipid Interactions}

A variety of lipid second messengers produced by phospholipases (PL) activate PKCs. The first described and well known pathway involves the receptor-mediated PLC activation that induces the hydrolysis of the membrane phosphatidylinositol 4,5-bisphosphate (PIP2), thus generating inositol 1,4,5-triphosphate (IP3) and DAG: IP3 releases free calcium ions from intracellular stores and DAG is also generated by receptor-mediated activation of PLD. In addition, PLA2 activation produces arachidonic acid, lysophosphatidylcholine, and cis-unsaturated fatty acids reported as activators and/or enhancing activators of several PKCs. ${ }^{12}$

$\mathrm{PKC}$ activation is not only regulated by protein-lipid interactions described so far, but also by protein-protein interactions. 


\section{Protein-Protein Interactions}

The receptor-regulated production of DAG and other lipids induce in PKC a change in localization and the phosphorylation of specific substrates. How can individual activated PKCs find their way close to the relevant substrates? In this case protein-protein interactions play an important role. Several proteins interact with PKCs with isoform selectivity; ${ }^{13}$ some proteins are direct substrates while others facilitate the interaction with the relevant substrates. For aPKCs, activation can be driven by intracellular localization through regulatory proteins and nuclear localization/export signals. ${ }^{8,9}$ Among the PKC-interacting proteins, scaffolding/adaptor proteins termed RACKs (receptors for activated C kinases) bind with isozyme selectivity PKC only after activation and direct the enzyme close to the relevant substrates. ${ }^{14}$ RACKs are proteins bearing seven repeats of the WD40 motif identified originally in the $\beta$ subunit of G proteins: WD40 motifs regulate protein-protein interactions. Up to now, two RACK proteins have been identified and characterized namely RACK1 (selective for PKC $\beta$ II) ${ }^{15}$ and RACK2 (selective for PKCE). ${ }^{16}$ RACKs are not substrates of the respective PKCs, upon PKC activation they colocalize and increase substrate phosphorylation by several fold. Because of the presence of seven WD repeats, RACKs bind and regulate a variety of other signaling enzymes. ${ }^{17}$ One of the most interesting breakthroughs within this field is the recognition that it is possible to inhibit the translocation and the function of individual PKC isozymes by peptides mimicking the sites of interaction between PKC and RACK. Moreover pseudo-RACK peptides can activate PKC without production of second messengers. ${ }^{18}$ By utilizing these peptides, specific functions have been recognized for individual PKC isoforms in both cardiac and neuronal homeostasis. ${ }^{19}$ As for the regulation of "inactive" PKCs, other scaffolding proteins termed RICKs (receptors for inactive $\mathrm{C}$ kinases) may influence their localization before activation. ${ }^{20}$

\section{PKC DOWNREGULATION}

In the membrane-bound form, PKC is two orders of magnitude more sensitive to dephosphorylation when compared to the soluble enzyme. Long-term activation of PKC results in dephosphorylation by phosphatases and thus an interaction with the chaperone heat shock protein 70 (Hsp70) occurs. ${ }^{21}$ At this point two pathways can be taken: one way in which Hsp70-bound PKC is rephosphorylated and recycled back as soluble newly reactivable enzyme; the other in which Hsp70 separates from PKC resulting in its association with cytoskeletal elements and eventual downregulation by proteolysis. ${ }^{8}$

\section{PKC ISOFORM-SPECIFIC BRAIN FUNCTIONS}

The roles of PKC isozymes in the brain are largely unknown, but experiments using knockout mice and isoform-specific inhibitors/activators seem to indicate that some functions are indeed regulated by specific PKC isoforms (TABLE 1). Studies in mouse lacking the neuron-specific PKC $\gamma$ were the first to be described. In this animal model, spatial memory was mildly affected and long-term synaptic potentiation 
TABLE 1. Selected functions of cPKC isozymes in neuronal tissues: knockout and peptide studies

\begin{tabular}{|c|c|c|c|}
\hline $\begin{array}{c}\text { PKC } \\
\text { isozyme }\end{array}$ & $\begin{array}{l}\text { Knockout } \\
\text { (reference) }\end{array}$ & $\begin{array}{l}\text { Peptide inhibitors } \\
\text { (reference) }\end{array}$ & $\begin{array}{l}\text { Peptide activators } \\
\text { (reference) }\end{array}$ \\
\hline $\mathrm{PKC} \alpha$ & Cerebellar LTD impairment (24) & ND & ND \\
\hline $\mathrm{PKC} \beta$ & Loss in fear conditioning (25) & $\begin{array}{l}\text { Astrocyte degenera- } \\
\text { tion (29) }\end{array}$ & ND \\
\hline $\mathrm{PKC} \gamma$ & $\begin{array}{l}\text { Hippocampal LTP impairment (22) } \\
\text { Loss of estrogen protection from } \\
\text { ischemia (23) } \\
\text { Ethanol/sedative hyposensitivity (26) }\end{array}$ & $\begin{array}{l}\text { Ethanol withdrawal } \\
\text { hyper-responsive- } \\
\text { ness (33) }\end{array}$ & ND \\
\hline PKC $\delta$ & ND & $\begin{array}{l}\text { Reduction of cere- } \\
\text { bral ischemic rep- } \\
\text { erfusion injury } \\
\text { (28) }\end{array}$ & $\begin{array}{l}\text { Attenuation of kainate } \\
\text { degeneration (31) }\end{array}$ \\
\hline $\mathrm{PKC} \varepsilon$ & Ethanol/sedative supersensitivity (26) $\mathrm{I}$ & Hyperalgesia (30) $\mathrm{F}$ & $\begin{array}{l}\text { Protection from oxygen/ } \\
\text { glucose deprivation (29) }\end{array}$ \\
\hline $\mathrm{PKC} \theta$ & Synapse elimination impairment (27) & ND & ND \\
\hline $\mathrm{PKC} \zeta$ & ND & $\begin{array}{l}\text { Decreased excito- } \\
\text { toxicity (32) }\end{array}$ & ND \\
\hline
\end{tabular}

NoTE: ND = not determined; LTD = long-term depression; LTP = long-term potentiation.

in hippocampus was impaired; ${ }^{22}$ these animals also present a reduced neuroprotection by estrogens after ischemia. ${ }^{23}$ In the PKC $\alpha$ null mice long-term synaptic depression is not inducible in the cerebellum ${ }^{24}$ while mice lacking PKC $\beta$ suffer from a deficit in both cued and contextual fear conditioning. ${ }^{25}$ The PKCE null mice indicate an involvement of this isoform in pain states and in the action of sedative drugs and in alcohol consumption. ${ }^{26}$ In the PKC $\theta$ knockout, a decreased synapse elimination is observed. ${ }^{27}$

Investigations with isoform-specific inhibitors/activators have shown that PKC $\delta$ inhibition reduces reperfusion-induced injury after stroke ${ }^{28}$ while inhibition of PKC $\beta$ I enhances astrocyte degeneration. ${ }^{29}$ PKC $\varepsilon$ and $\gamma$ inhibition are also involved in hyperalgesia, ${ }^{30}$ while activation of $\mathrm{PKC} \delta$ attenuates the kainate-induced cell death of cortical neurons. ${ }^{31}$ Additionally, $\mathrm{PKC} \zeta$ inhibition may protect from excitotoxic neuronal death ${ }^{32}$ while ethanol withdrawal hyper-responsiveness may be sensitive to selective inhibition of PKC $\gamma .{ }^{33}$ Moreover, mutational approaches point out that the PKC $\gamma$ gene is associated with animal models of Parkinson's disease ${ }^{34}$ and with cerebellar ataxia in humans. ${ }^{35}$

All these data suggest the possibility that interfering with PKC in an isoform-selective manner could control several aspects of neuronal homeostasis under both physiologic and pathologic conditions.

\section{CPKC IN PHYSIOLOGICAL BRAIN AGING}

A variety of functions related to $\mathrm{PKC}$ have been reported to be modified as a consequence of brain aging. In addition to changes at the molecular level, such as calci- 
um ion homeostasis, neurotransmitter release, and receptor regulation, important modifications occur in long term synaptic changes and thus in some forms of memory. In addition behavioral, genetic, elecrophysiological, and pharmacological evidence underscore the importance of PKC in learning and memory processes. ${ }^{4}$ Within this context, in the last few years we have investigated brain PKC homeostasis and its regulation during aging.

\section{Kinase Activity Shows Strain and Substrate-Dependent Changes}

We started by asking whether PKC function, evaluated with the conventional assay of histone phosphorylation in the presence of optimal concentrations of activators (calcium, PtdSer, DAG), was modified in different brain areas. We found that Sprague-Dawley rat cortex shows age-related decrease in spite of an increase of PKC activity detected in the hippocampus and no change in cerebellum. ${ }^{36}$ This effect proved to be strain-dependent because it was also observed in Fisher $344,{ }^{37}$ but not in Wistar rats, where kinase activity was unchanged in all brain areas (cortex, cerebellum, and hippocampus) and fractions (soluble and membrane) investigated ${ }^{38}$ (FIG. 1A, for the activity in cortex). Utilizing a selective brain substrate for PKC (i.e., purified protein B-50/GAP43) we were able to detect a significant impairment in
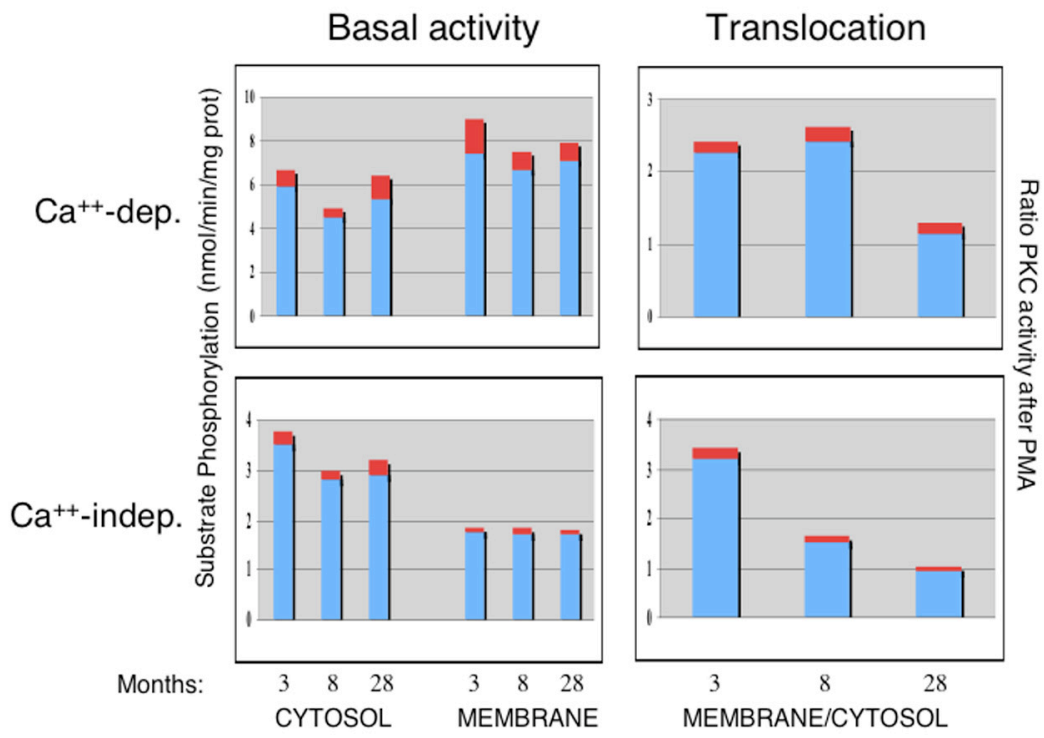

FIGURE 1. Calcium-dependent and -independent PKC activity and translocation in cortex from Wistar rats during aging. Calcium dependent PKC activity (A) and translocation (B) was assayed utilizing histone as substrate as described. ${ }^{38}$ Calcium-independent PKC activity (C) and translocation (D) was assayed utilizing $\left(\mathrm{Ser}^{25}\right) \mathrm{PKC}_{19-36}$ as substrate as described. ${ }^{41}$ Translocation is reported as ratio of activity in membranes and soluble fractions after treatment with PMA $160 \mathrm{nM}$ for $15 \mathrm{~min}$. Data are the mean values \pm SE (darker) from 7-9 individual measurements. 
PKC-dependent phosphorylation in cortical membranes from middle-aged (8 month old) and aged (28 month old) Wistar rats. B-50 phosphorylation was instead increased in the hippocampal membranes from the same aged Wistar rats. ${ }^{38}$

\section{cPKCs Translocation Is Impaired in Aged Rats}

In the previously described studies, PKC activity measurements were assessed in vitro under optimal conditions of activators and substrates, but this may not be the physiological milieu during aging. It is known that calcium ions, phospholipids, and substrates display changes during senescence that in some cases may be also areadependent.

To circumvent these variables, we analyzed PKC function in terms of activation/ translocation in response to phorbol esters challenge utilizing tissue slices. Upon short-term (15 min) low concentration $(160 \mathrm{nM})$ phorbol ester (PMA: phorbol 12myristate-13-acetate) treatment, the activation of PKC bypasses the availability of activators and the enzyme translocates from the cytosolic to the membrane compartment. This process is observed as a decrease in the cytosolic and an increase in the membrane-bound PKC activity. cPKC translocation appeared to be preserved up to middle age but was impaired in aged animals (Wistar) in both cortex (FIG. 1B) and hippocampus. ${ }^{38}$ This effect is independent of the strain utilized because it is observed also in aged Fisher 344 rats. ${ }^{39}$

\section{Transcription and Translation of cPKCs in Aging}

Given that the activity and translocation of PKC might be influenced by a differential expression of the PKC isoforms during aging, we analyzed the existence of changes at transcriptional level. The presence and regional distribution of $\mathrm{cPKCs}(\alpha$, $\beta$, and $\gamma$ ) mRNA isoforms were assessed by Northern hybridization. No modifications in the amount pattern of the different mRNAs were observed in aged Wistar rats, only a decrease in the $\alpha$ and $\beta$ signal that is already present at 8 months of age in cortex. ${ }^{38}$ Northern blot analysis allows quantification of mRNA in tissue homogenate but localized changes in specific brain regions may remain undetected due to the limitation of this approach. To further investigate any potential changes in PKC mRNA levels in discrete hippocampal and cortical regions, we performed in situ hybridization: aging did not modify in a significant manner the relative mRNA of the three calcium-dependent PKC isoforms in any area and subfield analyzed. ${ }^{38}$

The possibility that translational changes in PKC isoforms might occur during aging was then addressed by looking at the content of each specific isoform by Western analysis, in both soluble and particulate fractions. PKC $\alpha, \beta \mathrm{I}, \beta \mathrm{II}$, and $\gamma$ immunoreactivities were not modified in cytosolic and membrane fractions of cortex and cerebellum; only hippocampal PKC $\gamma$ was significantly increased at membrane level in aged animals. As we have speculated, ${ }^{38}$ this observation may be directly related to learning capabilities in aged animals. In fact, when analyzing learning performance on a water-maze task as a function of PKC $\gamma$ (as immunohistochemistry signal) in aged rats, Colombo and Gallagher recently found, in accord with our observations, that the worst performance was coupled to higher levels of PKC $\gamma$ in hippocampal CA1 and dentate gyrus regions. ${ }^{40}$ From our data we can add that this effect may be due to posttranslational changes because PKC $\gamma$ mRNA in the CA1 and dentate gyrus regions does not change in aged animals. ${ }^{38}$ 
TABLE 2. RACK1 levels in cortical membranes fractions in physiological and pathological brain aging

\begin{tabular}{lccccc}
\hline & $\begin{array}{c}\text { RACK1 immuno- } \\
\text { reactivity } \\
\text { (ODUs/ } \mu \mathrm{g} \\
\text { protein) }\end{array}$ & $\begin{array}{c}\text { Percent } \\
\text { of } \\
\text { young }\end{array}$ & $\begin{array}{c}\text { Percent } \\
\text { of } \\
\text { controls }\end{array}$ & $\begin{array}{c}\text { Ratio immuno- } \\
\text { reactivity RACK1 } \\
\text { (human cortex/ } \\
\text { internal standard) }\end{array}$ & Patients \\
\hline Young (3) & $208 \pm 22$ & 100 & 100 & $0.65 \pm 0.06$ & controls \\
Middle-aged (8) & $180 \pm 33$ & 86 & 53 & $0.35 \pm 0.08^{*}$ & $\begin{array}{c}\text { Alzheimer's } \\
\text { disease }\end{array}$ \\
Aged (28) & $94 \pm 8^{*}$ & 45 & & & \\
\hline
\end{tabular}

NotE: ODUs $=$ optical density units; values are expressed as means \pm SEM; $* P<0.01$ Dunnett's (rats) or Student's (patients) $t$ test; internal standard $=$ rat cerebellum membranes.

\section{Anchoring/Scaffolding of cPKCs}

The most consistent change in $\mathrm{cPKC}$ function during brain senescence (irrespective of strain and area investigated) appeared to be the lack of enzyme activation/ translocation. Changes in membrane lipid composition and impairments in transduction could explain such functional deficit. Owing to the reputed role of RACK proteins in directing activated PKC to relevant targets, we studied whether the agerelated impaired PKC translocation could be associated with changes in proteinprotein interactions. ${ }^{41}$ We observed that cortical levels of RACK1 were decreased in membranes prepared from aged rats (TABLE 2). Because of the reported specificity of RACK1 for PKC $\beta I I$, we measured the translocation of this isoform after PMA treatment. PKC $\beta$ II translocation to the membrane compartment was also deficient in tissue slices from aged animals. Recent findings have confirmed this age-related decrease in cortical RACK1 in aged Sprague-Dawley rats and also demonstrated a reduction in mRNA levels. ${ }^{42}$ This effect is sex specific, not being observed in female animals. Taken together, these data indicate that a deficit in RACK1 may contribute to the functional impairment in cPKC translocation detected in aged rats.

\section{nPKC AND APKC IN PHYSIOLOGICAL BRAIN AGING}

In order to complete the study of PKC during brain aging we also investigated the calcium-independent novel (nPKC) and atypical (aPKC) isoforms in the cortex. In agreement with the findings on $\mathrm{cPKCs}, \mathrm{PKC} \delta, \varepsilon, \eta$, and $\zeta$ remain constant as immunoreactive proteins in both soluble and membrane fractions. ${ }^{43}$ Accordingly, basal calcium-independent kinase activity did not change as function of age (FIG. 1C). On the other hand, calcium-independent PMA-dependent PKC translocation resulted in deficits in aged animals (FIG. 1D) as also confirmed by specific Western blotting analysis for PKC $\delta$ and $\varepsilon .{ }^{41}$ We have also investigated the levels of another anchoring protein reported to interact preferentially with the calcium-independent PKC $\varepsilon^{16}$ However the levels of RACK2 (utilizing antibodies to $\beta$ COP kindly provided by Dr. K.J. Harrison Lavoie) ${ }^{44}$ remain constant in membrane fractions from aging rats (unpublished results). Considering that RACK1 may interact, although with less affinity 
when compared to $\beta \mathrm{II}$, with $\mathrm{PKC} \delta$ and $\varepsilon,{ }^{15}$ it is thus possible that the decrease in RACK1 may affect calcium-independent PKC translocation as well.

Collectively all the reported data on physiological aging point to the general observation that at least in rat cortex during aging:

- calcium-dependent and -independent kinase activity under optimal conditions of activators remains constant throughout life;

- all PKC isoforms are preserved as basal immunoreactive protein expression, in spite of a decreased mRNA for PKC $\alpha$ and $\beta$ already present in adulthood;

- the translocation process upon PMA challenge is deficient for both calciumdependent and -independent PKC isoforms; and

- the anchoring protein RACK1 deficit in the membrane may contribute to the impairment in calcium-dependent and -independent PKC translocation.

\section{PKC IN PATHOLOGICAL BRAIN AGING}

PKC has been implicated in the neurodegeneration that occurs in Alzheimer's disease (AD). Besides deficits in neurotransmitters and growth factors activating $\mathrm{PKC}$, the enzyme itself and its responsiveness is modified in $\mathrm{AD}$ in central and peripheral tissues. ${ }^{43,45-48}$ The kinase $\mathrm{C}$ family is involved in the regulation of the metabolism of the amyloid precursor protein (APP) towards the non-amyloidogenic pathway. ${ }^{46}$ Of relevance to our previous studies, it was reported that there is a defect in PKC activation in AD brain in terms of marked loss of redistribution of cortical cytosolic PKC to the membrane fraction in response to activation with phorbol esters and $\mathrm{K}^{+}$depolarization. ${ }^{48}$ This was an observation with analogies with our previous investigations in aging rats that could be utilized to prove the relevance of the animal studies for human pathologies. We reasoned that, accordingly to our findings in rat brain during senescence, anchoring proteins could also be involved in the regulation of PKC activation process in Alzheimer's disease. The analysis of RACK1 in human frontal cortex autopsies indicate that when compared to age-matched controls AD patients have reduced expression of RACK1 in both soluble and membrane compartments (TABLE 2). ${ }^{49}$ The basal levels of PKC $\beta I I$ were also assessed and again, in agreement with our previous results, no pathology-related changes were observed in AD tissues, ${ }^{49}$ suggesting that it is not the expression of PKC that is deficient AD, but rather the mechanism of activation-anchoring that undergoes pathology-dependent changes.

\section{AGE-RELATED PKC ACTIVATION/ANCHORING IN NON-NEURONAL TISSUES}

We further explored whether the age-associated changes in PKC activation/compartmentalization could be extended to non neuronal tissues. For this purpose we utilized the model of rat alveolar macrophages. These cells secrete tumor necrosis factor $\alpha(\mathrm{TNF} \alpha)$ in response to lipopolysaccharide (LPS) through a PKC-mediated transduction machinery. Macrophages from old rats secrete less TNF $\alpha$ in the pres- 
ence of LPS; the translocation of PKC $\beta$ II upon LPS is impaired in aged animals, where immunoreactive RACK1 appears to be decreased by roughly $50 \% .{ }^{50}$

Other studies have reported in senescent myocardium a disrupted PKC $\alpha$ and PKC $\varepsilon$ translocations to membrane in response to $\alpha 1$ receptor activation, associated with a reduction in the respective anchoring proteins RACK1 and RACK2. ${ }^{51}$

Moreover, recent reports on peripheral blood human leukocytes from aged donors have demonstrated a decreased expression of RACK1 that impairs the PKC $\beta$-dependent LPS-induced TNF $\alpha$ production and the mitogen-dependent proliferation. ${ }^{52}$

All these data strengthen the notion that an age-dependent RACK1 deficit may impair PKC translocation and related functions in peripheral tissues as well.

\section{INTERVENTIONS ON PKC SIGNAL TRANSDUCTION IN AGING}

A number of conditions have been reported to counteract the blunted PKC transmission and/or anchoring mechanisms during aging. One of the first reports dealt with exogenous PtdSer that appeared to counteract the blunted PKC-dependent phosphorylation of hippocampal protein B50/GAP43. ${ }^{53}$ In the same brain area, caloric restriction and antioxidant (N-tert-butyl- $\alpha$-phenylnitrone) treatment can restore phorbol ester-dependent synapsin I phosphorylation. ${ }^{54}$ In peripheral tissues a smaller reduction in lymphocyte $\mathrm{PKC}$ activation can be shown in aged men practicing aer-
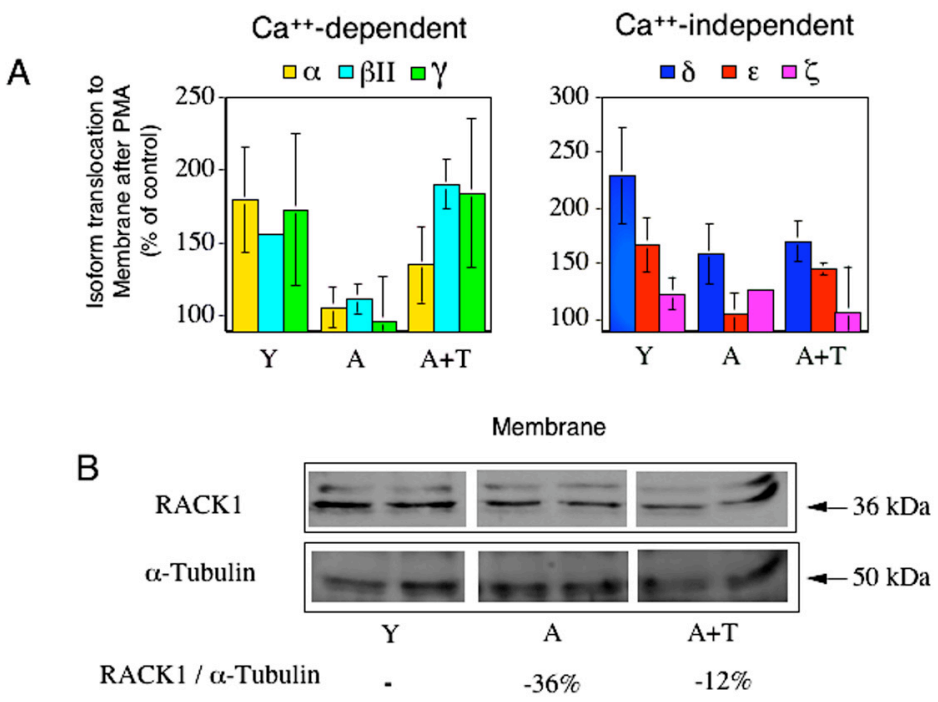

FIGURE 2. PKC isoforms translocation (A) and RACK1 levels (B) from cortex of aged rats after pineal transplant. Membrane PKC isozyme translocation and RACK1 levels were assayed as described. ${ }^{41}$ PKC translocation was induced with treatment with PMA $160 \mathrm{nM}$ for $15 \mathrm{~min}$ in cortical slices from $4-5$ rats for each group. Values are means \pm SD of 3 determinations. RACK1 IR was assayed in frozen aliquots under unstimulated conditions. $\mathrm{Y}=$ young, 3-month-old rats; $\mathrm{A}$ = aged, 25-month-old rats; $\mathrm{A}+\mathrm{T}=$ aged 23-month-old rats subjected, at 18 months of age, to a transplant of the pineal gland from young animals. In $\mathbf{A}$ each group of three bars represents, from left to right, $\alpha, \beta I I$, and $\gamma$, respectively, for $\mathrm{Ca}^{++}$ dependent; and $\delta, \varepsilon$, and $\delta$, respectively, for $\mathrm{Ca}^{++}$-independent. 
obic fitness ${ }^{55}$ while chronic exercise training in rats partially reverses $\alpha 1$-mediated activation of cardiac PKC. 56

In other studies it has been reported that the age-related loss of RACK1, as both messenger RNA and protein, observed in the hippocampus of aged rats can be restored by a two weeks treatment with dehydroepiandrosterone. ${ }^{57}$ Accordingly with this findings, this steroid restores RACK1 levels in aged rat alveolar macrophages and splenocytes. ${ }^{58}$

Recently, in collaboration with Drs. Walter Pierpaoli and Daniele Bulian, we have obtained preliminary results on PKC activation in the brain of aged rats ( 25 months old) in which implantation of a pineal gland from young rats ( 3 months old) into the thymus was performed at 18 months. Our findings seem to indicate that pineal implant partially restores the aging-associated impairment of PKC translocation in cortex, at least for $\beta$ II and $\varepsilon$ isoforms (FIG. 2A). Additionally, pineal transplant also induces a partial recovery $(-12 \%$ with respect to young animals values) in RACK1 levels that were decreased by $36 \%$ in aged animals (FIG. 2B).

In rodents this model previously also showed a prolongation of survival and of $\mathrm{T}$ cell-mediated immune function. ${ }^{59}$ Moreover a normalization of brain cortical $\beta 1$ adrenergic receptor density ${ }^{60}$ and of hippocampal LHRH receptors ${ }^{61}$ has been reported in aged transplanted animals in comparison with controls with no transplants.

\section{DISCUSSION}

$\mathrm{We}^{1,36,38,41}$ and several other groups ${ }^{37,39,53,54}$ have provided evidence that PKC is a signal transduction system that is affected in aged animals in neuronal tissues and this observation can be extended to non-neuronal tissues as well, ${ }^{50,51}$ underlining the importance of this finding for aging mechanisms in general terms.

Calcium-dependent PKC translocation is blunted as consequence of aging irrespective of animal strain and area investigated (at least in brain cortex, hippocampus, and cerebellum ${ }^{38}$ ) and in general no changes at isoform basal levels are evident. In cortical tissues, calcium-independent PKC translocation is also deficient despite the absence of changes at isoform basal levels.

The only exception is presented by PKC $\gamma$ isoform, which increases in the hippocampal membranes of aged animals. ${ }^{38}$ This may be related to the control of plasticity phenomena at brain level and thus to memory. This observation was at first sight unexpected mainly because in young animals hippocampal $\mathrm{PKC} \gamma$ levels are related to better performance in different memory tasks. ${ }^{62}$ However, analyzing PKC $\gamma$ levels in aged rats as function of learning performance on a water-maze paradigm, Colombo and Gallagher found that in the animals with the worst memory, performance parallels higher levels of hippocampal membrane-bound PKC $\gamma$ in CA1 and dentate gyrus regions. ${ }^{40}$ Taken together these data underline the possibility that memory impairment in aged rats may result, at least partially, from a dysregulation of PKC $\gamma$. Considering that $\mathrm{PKC} \gamma$ is specifically expressed in the nervous system, higher levels of membrane-bound $\mathrm{PKC} \gamma$ in unstimulated conditions may represent an attempt to compensate a functional deficit occurring in the translocation process of this specific isoform during senescence. In agreement with this concept, during aging one of the key factors controlling PKC activation/relocation-RACK1 protein-decreases thus contributing to the inability to sustain PKC translocation. ${ }^{41}$ These observations can 
be extended to non neuronal tissues in physiological animal aging ${ }^{50}$ and to pathological brain aging-Alzheimer's disease-where a deficient PKC translocation process occurs, ${ }^{48}$ concomitantly with a decrease in RACK1 anchoring protein, indicating that the enzyme is preserved - but not the mechanism for its activation. ${ }^{49}$ It is interesting to note that a defective RACK1 system is observed also in brain cortex of Down syndrome fetuses (early second trimester of gestation). ${ }^{63}$

The relevance of RACK1 changes with respect to PKC deserves further comment. Van der Zee and coworkers have investigated in great detail cPKCs in aged rabbit hippocampus through immunohistochemical and subcellular fractionation studies. ${ }^{64}$ With the former, they observed an increase in immunoreactivity in selected subregions for $\beta$ and $\gamma$, and with the latter they found a dramatic decrease for all the isoforms at membrane level associated with a robust loss of RACK1 protein $(-96 \%)$. Their interpretation is that the increase in immunoreactivity is due to the loss of RACK1 (interacting with PKC) thus allowing more antigenic sites on PKC to be detected immunohistochemically. ${ }^{64}$ Nonetheless they report unpublished findings on increased PKC $\gamma$ in hippocampus of aged rats and emphasize the relevance of RACK1 loss in the dysregulation of PKC system in aged rabbits as well. These data suggest that, in addition to strain-specific changes, there are also speciesspecific changes in $\mathrm{PKC}$ isoforms during aging.

The relevance of RACK1 in regulating PKC function is further underscored by results of studies on brain PKC/RACK1 interdependence in morphine-dependent rats. ${ }^{65}$ In addition, in a condition in which PKC is hyperfunctional (bipolar patients) PKC activation by PMA is upregulated, and this phenomenon goes in parallel with an increased association of various PKCs with RACK1.66

Various conditions affecting PKC-lipid interactions (treatment with exogenous phosphatidylserine ${ }^{53}$ and antioxidants, ${ }^{54}$ for example) can counteract the age-related changes in PKC detected during brain aging. Additionally, the PKC translocation deficit occurring during senescence may be prevented by hormonal (dehydroepiandrosterone) treatment ${ }^{57}$ or by pineal transplant (FIG. 2) acting through a recovery in brain RACK1 levels. Concerning pineal transplant, we may only speculate that in transplanted aged animals a release of some peptides that influence positively brain functional homeostasis could be involved. ${ }^{59}$ As far as the recovery in RACK1 levels is concerned, it is not known how this process can be regulated, but recent data have documented that NF- $\kappa B$ is a relevant transcription factor for RACK1 gene. ${ }^{67}$ The same authors provided evidence that RACK1 promotes neuronal cell survival. It is interesting to note that inhibition of NF- $\mathrm{\kappa B}$ increases beta amyloid neuronal apoptosis, ${ }^{68}$ suggesting that RACK1 deficit in Alzheimer's disease may be dependent on a defect in NF- $\mathrm{KB}$ activation. Along this line, it is important to note that the activation of PKC with bryostatin 1 (a non-tumor promoter activator of the enzyme) decreases beta amyloid accumulation and premature death and improves behavioral outcomes in mice models of Alzheimer's disease. ${ }^{69}$ Moreover rasagiline, a monoamine oxidase B inhibitor, facilitates in vivo non amyloidogenic processing of APP in rat hippocampus through increase in PKC/RACK1 levels. ${ }^{70}$ It is thus tempting to postulate that it is possible to interfere directly with the PKC activation/anchoring machinery to counteract age-related physiological or pathological changes in brain functions. FIGURE 3 summarizes how PKC is activated in physiological conditions and how a decrease in RACK1 anchoring protein may affect such a process and induce a decreased response. 


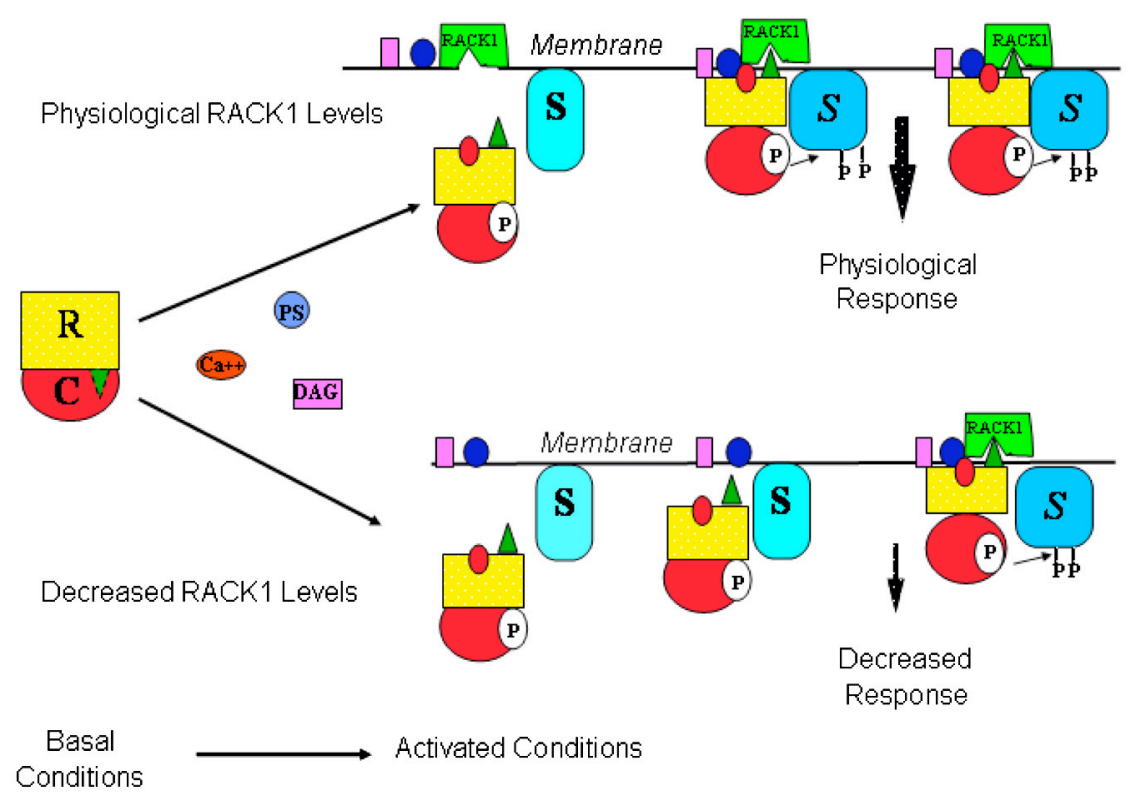

FIGURE 3. Activation of PKC and the role of anchoring/scaffolding protein RACK1. The figure depicts the involvement of RACK1 anchoring protein in the mechanism of cPKC translocation and phosphorylation of a relevant substrate. A decrease in RACK1 is associated with blunted translocation of the activated PKC with a consequent decrease in the functional response. Under basal conditions RACK1 binding site on PKC (triangle) is masked and is exposed only after activation. $\mathrm{C}=\mathrm{PKC}$ catalytic subunit, $\mathrm{R}=\mathrm{PKC}$ regulatory subunit, $\mathrm{Ca}^{2+}=$ calcium, $\mathrm{PS}=$ phosphatidylserine, $\mathrm{DAG}=$ diacylglycerol, $\mathrm{S}=$ substrate, $S=$ substrate phosphorylated $(\mathrm{P})$.

Moreover, RACK-PKC interactions have made it possible to introduce into preclinical studies PKC isoform-selective probes (inhibitors and activators) that have demonstrated isoform-specific effect in $\operatorname{cardiac}^{40}$ and neuronal functions (TABLE 1). Such compounds are also increasing our understanding of pathological states and look promising for a therapeutic use. For instance, PKC $\varepsilon$ and PKC $\delta$ interacting peptides show encouraging results in the control of ischemic phenomena at both cardiac and neuronal levels. ${ }^{19,28,29,31}$

Modulating the PKC isoform activation/anchoring mechanism offers an interesting additional approach for developing innovative therapeutic tools in diverse physiologic and pathologic conditions. ${ }^{71,72}$

\section{ACKNOWLEDGMENTS}

This work was partially supported by a grant from Italian Ministero Sanità/Regione Lazio (Progetto Alzheimer) to F.B. 
[Competing interests: The authors declare that they have no competing financial interests.]

\section{REFERENCES}

1. Battaini, F. et al. 1997. The role of anchoring protein RACK1 in PKC activation in the aging rat brain. Trends Neurosci. 20: 410-415.

2. WiCKELGREN, I. 1996. For the cortex, neuron loss may be less than thought. Science 273: 48-50.

3. Rapp P.R. \& M. Gallager. 1996. Preserved neuron number in the hippocampus of aged rats with spatial learning deficits. Proc. Natl. Acad. Sci. USA 93: 9926-9930.

4. Nogues, X. et al. 2003. Protein Kinase C. In Memories Are Made of These: From messengers to molecules. G. Riedel \& B. Platt, Eds.: 383-410: Landes Bioscience. Georgetown, TX.

5. Amadio, M. et al. 2004. Emerging targets for the pharmacology of learning and memory. Pharmacol. Res. 50: 111-122.

6. NishizUKA, Y. 2003. Discovery and prospect of protein kinase C research: epilogue. J. Biochem. (Tokyo). 133: 155-158.

7. TANAKA, C \& Y. NishizUKa. 1994. The protein kinase $\mathrm{C}$ family for neuronal signalling. Ann. Rev. Neurosci. 17: 551-567.

8. Newton, A.C. 2003. Regulation of the ABC kinases by phosphorylation: PKC as a paradigm. Biochem. J. 370: 361-371.

9. PareKh, D.B.,W. Ziegler \& P.J. Parker. 2000. Multiple pathways control PKC phosphorylation. EMBO J. 19: 496-503.

10. RYKX, A. et al. 2003. Protein kinase D: a family affair. FEBS Lett. 546: 81-86.

11. Balendran, A. et al. 2000. Further evidence that 3-phosphoinositide-dependent protein kinase-1 (PDK1) is required for the stability and phosphorylation of protein kinase C (PKC) isoforms. FEBS Lett. 484: 217-223.

12. NishizukA, Y. 1995. Protein kinase $\mathrm{C}$ and lipid signaling for sustained cellular responses. FASEB J. 7: 484-496.

13. Poole, A.W. et al. 2004. PKC-interacting proteins: from function to pharmacology. Trends Pharmacol. Sci. 25: 528-535.

14. Mochly-Rosen, D. 1995. Localization of protein kinases by anchoring proteins: a theme in signal transduction. Science 268: 247-251.

15. Ron, D. et al. 1994. Cloning of an intracellular receptor for protein kinase C: a homolog of beta subunit of G proteins. Proc. Natl. Acad. Sci. USA 91: 839-843.

16. CsuKaI, M. et al. 1997. The coatomer protein $\beta^{\prime}$-COP, a selective binding protein (RACK) for protein kinase C epsilon. J. Biol. Chem. 272: 29200-29206.

17. MCCAhill, A. et al. 2002. The RACK1 scaffold protein: a dynamic cog in cell response mechanisms: Mol. Pharmacol. 62: 1261-1273.

18. Schechtman, D. \& D. Mochly-Rosen. 2001. Adaptor proteins in protein kinase Cmediated signal transduction. Oncogene 20: 6339-6347.

19. Csukai, M. \& D. Mochly-Rosen. 1999. Pharmacologic modulation of protein kinase C isozymes: the role of RACKs and subcellular localisation. Pharmacol. Res. 39: 253-259.

20. Mochly-Rosen, D. \& A. Gordon. 1998. Anchoring proteins for protein kinase C: a means for isozyme selectivity. FASEB J. 12: 35-42.

21. GAo, T. \& A.C. Newton. 2002. The turn motif is a phosphorylation switch that regulates the binding of Hsp70 to protein kinase C. J. Biol. Chem. 277: 31585-31592.

22. Abeliovich, A. et al. 1993. Modified hippocampal long term potentiation in PKC gamma-mutant mice. Cell, 75: 1253-1262.

23. HAYASHI, S. et al. 2005. Involvement of gamma protein kinase $\mathrm{C}$ in estrogen-induced neuroprotection against focal brain ischemia through $\mathrm{G}$ protein-coupled estrogen receptor. J Neurochem. 93: 883-891.

24. LeITGES, M. et al. 2004. A unique PDZ ligand in PKC $\alpha$ confers induction of cerebellar long-term synaptic depression. Neuron 44: 585-594. 
25. WeEber, E.J. et al. 2000. A role for the $\mathrm{b}$ isoform of protein kinase $\mathrm{C}$ in fear conditioning. J. Neurosci. 20: 5906-5914.

26. HoDGE, C.W. et al. 1999. Supersensitivity to allosteric GABA(A) receptor modulators and alcohol in mice lacking PKC epsilon. Nat. Neurosci. 2: 245-254.

27. LI, M.X. et al. 2004. The role of the theta isoform of protein kinase C (PKC) in activity-dependent synapse elimination: evidence from the PKC theta knock-out mouse in vivo and in vitro. J. Neurosci. 24: 3762-3769.

28. BRIGHT, R. et al. 2004. Protein kinase C delta mediates cerebral reperfusion injury in vivo. J. Neurosci. 24: 6880-6888.

29. WANG, J. et al. 2004. Cell-specific roles for epsilon and beta1-PKC isozymes in protecting cortical neurons and astrocytes from ischemia-like injury. Neuropharmacology 47: 136-145.

30. SWEITZER, S.M. et al. 2004. Exaggerated nociceptive responses on morphine withdrawal: roles of protein kinase C epsilon and gamma. Pain 110: 281-289.

31. JUNG, Y.S. et al. 2005. Activation of protein kinase C-delta attenuates kainate-induced cell death of cortical neurons. Neuroreport 16: 741-744.

32. Koponen, S. et al. 2003. Prevention of NMDA-induced death of cortical neurons by inhibition of protein kinase C zeta. J. Neurochem. 86: 442-450.

33. Li, H.F., D. Mochly-Rosen \& J.J. Kendig. 2005. Protein kinase C gamma mediates ethanol withdrawal hyper-responsiveness of NMDA receptor currents in spinal cord motor neurons. Br. J. Pharmacol. 144: 301-307.

34. CRAIG, N J. et al. 2001. A candidate gene for human neurodegenerative disorders: a rat PKC gamma mutation causes a Parkinsonian syndrome. Nat. Neurosci. 4: 10611062 .

35. YABE, I. et al. 2003. Spinocerebellar ataxia type 14 caused by a mutation in PKC gamma. Arch. Neurol. 60: 1749-1751.

36. Battaini, F. et al. 1990. Regulation of phorbol ester binding and protein kinase C activity in aged rat brain. Neurobiol. Aging 11: 563-566.

37. Meyer, M. et al. 1994. Effect of peroxidation and aging on rat neocortical Ach release and PKC. Neurobiol. Aging 15: 63-67.

38. Battaini, F. et al. 1995. Protein kinase C activity, translocation and conventional isoforms in aging rat brain. Neurobiol. Aging 16: 137-148.

39. Friedman, E. \& H.-Y. WANG. 1989. Effect of age on brain cortical PKC and its mediation of 5-hydroxytryptamine release. J. Neurochem. 52: 187-192.

40. Colombo, P.J. \& M. Gallager. 2002. Individual differences in spatial memory among aged rats are related to hippocampal PKC gamma immunoreactivity. Hippocampus 12: 285-289.

41. Pascale, A. et al. 1996. Functional impairment in PKC by RACK1 (receptor for activated Kinase C1) deficiency in aged rat brain cortex. J. Neurochem 67: 2471-2477.

42. Sanguino, E. et al. 2004. Prevention of age-related changes in rat cortex transcription factor activator protein-1 by hypolipidemic drugs. Biochem. Pharmacol. 68: 14111421.

43. Pascale, A., S. Govoni \& F. Battaini. 1998. Age-related alteration of PKC, a key enzyme in memory processes. Mol. Neurobiol. 16: 49-62.

44. Harrison-Lavoie, K.J. et al. 1993. A $102 \mathrm{kDa}$ subunit of a Golgi associated particle has homology to beta subunits of trimeric G proteins. EMBO J. 12: 2847-2853.

45. Battaini, F. 2001. Protein kinase $\mathrm{C}$ isoforms as therapeutic targets in nervous system disease states. Pharmacol. Res. 44: 353-361.

46. RACCHI, M. \& S. GovonI. 1999. Rationalizing a pharmacological intervention on the amyloid precursor protein metabolism. Trends Pharmacol. Sci. 20: 418-423.

47. EtcheberRigaray, R. \& S. Bhagavan. 1999. Ionic and signal transduction alterations in Alzheimer's disease: relevance of studies on peripheral cells. Mol. Neurobiol. 20: 93-109.

48. Wang, H.-Y., M.R. Pisano \& E. Friedman. 1994. Attenuated PKC activity and translocation in Alzheimer's disease brain. Neurobiol. Aging 15: 293-298.

49. Battaini, F. et al. 1999. Protein kinase C anchoring deficit in postmortem brains of Alzheimer's disease patients. Exp. Neurol. 159: 559-564. 
50. Corsini, E. et al. 1999. A defective PKC anchoring system underlying age-associated impairment in TNF-alpha production in rat macrophages. J. Immunol. 163: 3468 3473.

51. KorZICK, D.H. et al. 2001. Diminished alpha 1-adrenergic-mediated contraction and translocation of PKC in senescent rat heart. Am. J. Physiol. Heart Circ. Physiol. 281: H581-H589.

52. Corsini, E. et al. 2005. Age-related decline in RACK-1 expression in human leukocytes is correlated to plasma levels of dehydroepiandrosterone. J. Leukoc. Biol. 77: 247-255.

53. GianotTi, C. et al. 1993. B-50/GAP43 phosphorylation in hippocampal slices from aged rats: effects of phosphatidylserine administration. Neurobiol. Aging 14: 401-406.

54. ECKLES, K.E. et al. 1997. Amelioration of age-related deficits in the stimulation of synapsin phosphorylation. Neurobiol. Aging 18: 213-217.

55. WANG, H.-Y. et al. 2000. Age-related decreases in lymphocyte protein kinase C activity and translocation are reduced by aerobic fitness. J. Gerontol. A Biol. Sci. Med. Sci. 55: B545-555

56. Korzick, D.H. et al. 2004. Chronic exercise improves myocardial inotropic reserve capacity through alpha1-adrenergic and protein kinase C-dependent effects in senescent rats. J. Gerontol. A Biol. Sci. Med. Sci. 59: 1089-1099.

57. RACCHI, M. et al. 2001. Dehydroepiandrosterone and the relationship with aging and memory: a possible link with protein kinase $\mathrm{C}$ functional machinery. Brain Res. Rev. 37: 287-293.

58. CoRsini, E. et al. 2002. In vivo dehydroepiandrosterone restores age-associated defects in PKC signal transduction pathway and related functional responses. J. Immunol. 168: $1753-1758$.

59. Pierpaoli, W. \& W. Regelson. 1994. Pineal control of aging: effect of melatonin and pineal grafting on aging mice. Proc. Natl. Acad. Sci. USA 91: 787-791.

60. VITICCHI, C. et al. 1994. Brain cortex alpha and beta adrenoceptors are differentially modulated by pineal graft in aging mice. Ann. N.Y. Acad. Sci. 719: 448-453.

61. Pierpaoli, W. et al. 1997. Circadian melatonin and young to old pineal grafting postpone aging and maintain juvenile conditions of reproductive functions in mice and rats. Exp. Gerontol. 32: 587-602.

62. VAN DeR ZeE, E.A., P.G. Luiten \& J.F. Disterhoft. 1997. Learning-induced alterations in hippocampal PKC-gamma immunoreactivity: a review and hypothesis of its functional significance. Prog. Neuropsychopharmacol. Biol. Psych. 3: 531-572.

63. Peyrl, A. et al. 2002. Aberrant expression of signalling-related proteins 14-3-3 gamma and RACK1 in fetal Down syndrome brain (trisomy 21). Electrophoresis 23: $152-157$.

64. VAN DER ZEE, E.A. et al. 2004. Aging-related alterations in the distribution of $\mathrm{Ca}(2+)-$ dependent PKC isoforms in rabbit hippocampus. Hippocampus 14: 849-860.

65. Escriba, P.V. \& J.A. Garcia-Sevilla. 1999. Parallel modulation of receptor for activated $\mathrm{C}$ kinase 1 and protein kinase $\mathrm{C}$-alpha and beta isoforms in brains of morphinetreated rats. Br. J. Pharmacol. 127:343-348.

66. WANG, H.-Y. \& E. FRIEDMAN. 2001. Increased association of brain PKC with the receptor for activated C kinase 1 (RACK1) in bipolar affective disorder. Biol. Psych. 50: 364-370.

67. CHOI, D.-S. et al. 2003. The mouse RACK1 gene is regulated by nuclear factor-kB and contributes to cell survival. Mol. Pharmacol. 64: 1541-1548.

68. KALtSCHMidT, B. et al. 1999. Inhibition of NF-kappa B potentiates amyloid beta-mediated neuronal apoptosis. Proc. Natl. Acad. Sci. USA. 96: 9409-9414.

69. Etcheberrigaray, R. et al. 2004. Therapeutic effects of PKC activators in Alzheimer's disease transgenic mice. Proc. Natl. Acad. Sci. USA 101: 11141-11146.

70. BAR-AM, O. et al. 2004. Regulation of protein kinase $\mathrm{C}$ by the anti-Parkinson drug, MAO-B inhibitor, rasagiline, and its derivatives in vivo. J. Neurochem. 89: 1119-1125.

71. WAY, K.J., E. CHOU \& G.L. KING. 2000. Identification of PKC-isoform-specific biological actions using pharmacological approaches. Trends Pharmacol. Sci. 21: 181-187.

72. DeMPSEY, E.C. et al. 2000. Protein kinase $\mathrm{C}$ isozymes and the regulation of diverse cell responses. Am. J. Physiol. Lung Cell. Mol. Physiol. 279: 429-438. 